\section{Engineering in the University of Glasgow}

IN less troublous times professional engineers all the world over would undoubtedly have wished to collaborate in celebrating the centenary of so important an event as the founding in 1840 of the regius chair of civil engineering and mechanics at the University of Glasgow. The second occupant of the chair, Prof. W. J. Macquorn Rankine, was an exceptionally brilliant man to whom all fields of knowledge seemed alike, and there are few branches of engineering science to which he did not make some notable contribution. In his time there was no thought of the expansion that was soon to take place, which now makes separate subjects of civil, mechanical and electrical engineering. As Engineering of September 27 points out, he was also an accepted authority on naval architecture. His influence was, and still remains, potent in many branches of design. The Glasgow Herald of September 16 says that he was "the first really powerful thinker in this country to bring the highest mathematical resources to bear on engineering practice".

Rankine died in 1872 and was succeeded by James Thomson, brother of Lord Kelvin, who was one of the earliest to develop the large-size centrifugal pump. In 1889 he was followed by Archibald Barr, who will long be remembered for his collaboration with Dr. Stroud in the production of the Barr and Stroud range-finder. He also left an enduring monument in the James Watt Engineering Laboratories of the University which he initiated. Barr's successor was the late Prof. J. D. Cormack, during whose tenure of the chair the centenary of the death of James Watt provided an occasion for the establishment of two new chairs, in heat engines and electrical engineering. They were actually founded in 1921, and with the existing John Elder chair of naval architecture, completed (at least, for the time being) the subdivision on modern lines of the comprehensive curriculum that Rankine had undertaken singlehanded, and which his own work had done so much to expand. It would be interesting to speculate how the popular attitude towards engineering in general would have been affected if its study had continued under the earlier title of 'natural philosophy'.

\section{Electric Utilities at the New York World's Fair}

IN the August issue of the Edison Electric Institution Bulletin, Mr. Gardner Boyd sums up the results of the first hundred days of the electric utilities exhibits at the New York World's Fair. When the Fair opened its gates on April 30, the electric utility industry presented two separate exhibits to the public. One was designed to give visitors an understanding of the public service objectives and their contributions to present-day living. The other was planned to show farmers the many ways in which electricity will serve them with profit. It has been said that so far the attendance at the Fair has been poor. This is true in comparison with standards required for profitable operation determined by the Fair management in advance of the opening; but so far as the electric utilities exhibit is concerned, attendance has been excellent both from the numerical point of view and from the qualitative aspect. To August 15, the total number of visitors to the main exhibit-Forward March of America-was $3 \frac{1}{8}$ millions. It has not been possible to make a continuous count of visitors to the electrified farm. From spot checks made frequently and compared with attendance at Forward March of America for the same periods, it appears from these comparisons that the farm draws regularly 75-80 per cent as large an attendance as Forward March of America, and that the total attendance at the two exhibits up to August 15 was approximately six millions.

At the farm there is an information bureau to which many visitors turn. Primarily they want to find out more about the various appliances and pieces of electrical equipment demonstrated at the farm. In order that they may be fully served, they are asked to fill in cards giving their names and home address, the appliances about which they want information and the name of the electric utility that serves them. Many thousands of these cards have been filled up. The information on the cards is promptly forwarded to the manufacturers and others who contributed material and equipment used on the farm, and to the utility companies serving the inquiries named.

\section{Applications of Synthetic Rubber}

IN an article entitled "Synthetic Rubber" appearing in the Engineer of September 13, Mr. A. E. Williams reviews the progress made with the synthetic rubber called neoprene, which was first developed in the United States about seven years ago by the Du Pont Company and is now manufactured by Imperial Chemical Industries Ltd. The starting point for neoprene is calcium carbide ; its properties can be varied by incorporating different substances in various proportions. Generally speaking, the initial cost of synthetic rubber is higher than that of natural rubber, but owing to its resistance to temperatures above $140^{\circ} \mathrm{F}$. and to acids and oils, it proves much cheaper in the long run. Exhaustive tests have been made to show its resistance to oil, and in one of these, whereas the tensile strength of natural rubber fell to 25 per cent of its original value, the strength of neoprene was reduced only to 93 per cent. It has many uses, among which $\mathrm{Mr}$. Williams mentions those for driving belts, the bonding of metals, inking rollers for printing machines, hoses for petrol and oil, the protection of insulated electric cables, seals for refrigerating apparatus and the manufacture of flexible ebonite, a substance finding many different applications in industry.

\section{Hemp Drug Addiction in India}

THE October issue of the British Jous , wo of Inebriety contains an instructive article by Brevet-Colonel R. N. Chopra and Captain G. S. Chopra of the School of Tropical Medicine, Calcutta, on the present position of hemp drug addiction in India. Hemp drugs in India are at present used in three forms, namely, bhang, which is taken as a beverage, while ganja, 
which is nearly four or five times more potent, and charas, the effects of which are even stronger than those produced by ganja, are mostly smoked. The cultivation of the hemp plant which grows wild in Northern India along the southern slopes of the Himalayas is strictly controlled for narcotic purposes. The total consumption of hemp drugs in British India during 1934-35 amounted to 1,031,496 lb.

According to the writers there are at least between 855,844 and $1,000,000$ hemp drug addicts in India, or approximately $0.5-1$ per cent of the total population. The main causes of addiction in order of frequency are association with other addicts, religious and emotional factors, substitution for other drugs, disease and minor ailments, and hard work, worry or strain. The commonest age to contract the habit is between twenty-one and thirty. The effects of the drug on the central nervous system can be divided into three stages : first, the stage of primary stimulation and excitement; secondly, the stage of depression and anæsthesia; and thirdly, the stage of secondary stimulation and excitement. Moderate habitual use may not be attended with harmful effects, but continued excessive indulgence impairs the normal functioning of the nervous system, renders the addict incapable of mental exertion and causes general debility and premature decay.

\section{Robert Boyle}

Axтноуян Robert Boyle (1627-1691) is well known for his law of compression of gases and for his clear definition of a chemical element (given in his "Sceptical Chymist", 1661), his many other services to chemistry and physics are less appreciated. M. Schofield (Chem. and Ind., 59, 615; 1940) has sketched some of these. Boyle's work in physics centred around his air pump, several models of which were constructed, and his experiments in a vacuum are of considerable interest, particularly in connexion with the barometer, the fact that sound is not propagated in a vacuum, and the boiling of water under reduced pressure. Experiments on freezing mixtures and hydrostatics, including the measurement of specific gravities, were also carried out by Boyle. In the field of chemistry he criticized the prevailing views on elements and pointed the way to a correct view of these, made experiments on combustion which emphasized the importance of the air, investigated the action of acids and alkalis on indicators, prepared phosphorus and ether, and was near the correct interpretation of respiration.

\section{Dr. Désire Bourneville}

Dr. Désirḱ Maglotre Bournevinle, a pioneer in the welfare of defective children, was born at Garencières in Normandy on October 21, 1840. He studied medicine in Paris, where he qualified in 1870. Three years later he founded Le Progrès Médical, which soon became one of the leading French medical journals. In 1879 he was appointed senior physician to the Bicêtre infirmary, where he took charge of a service almost entirely devoted to idiocy and other forms of mental defect in children and published the
Comptes revitus de Bicetre. In the following year he founded the Archives de Neurologie under the patronage of Charcot, whose works he had edited some years previously. Bourneville was one of the first in France to confirm Hertoghe's observations on thyroid cachexia and to prove the value of thyroid medication. He was also the first to describe the association of sclerotic nodules in the brain with mental defect and epilepsy which is known as tuberous sclerosis. $\mathrm{He}$ took an active part in the laicization of hospitals and in the foundation of training schools for nurses at La Salpêtrière, Lariboisière and Pitié hospitals. In 1905 he retired from the Bicêtre infirmary and was appointed director of the Vallée Foundation for the treatment of idiots and mentally defective children. He died on May 28, 1909.

\section{Luigi Bodio}

Lurgr BoDro, a celebrated Italian statistician, was born at Milan on October 12, 1840. After serving as lecturer in economics in the Technical Schools of Leghorn, Milan and Venice, he was appointed first permanent secretary of the Central Office of Statistics and in 1878 its director. In 1885 he was elected secretary to the International Institute of Statistics and in 1905 director. In 1901 he was made a senator of Italy. His writings were numerous and varied, the most important being on external commerce (1862), statistics in relation to politics, economics and allied sciences (1869), movement of population in Italy and other European States (1878) and Italian emigration (1894). He died on November 2. 1920.

\section{Amerindian Relics}

Some notable additions to the collections of the Smithsonian Institution illustrating the culture and history of the North American Indian peoples are recorded in communications recently issued by the Institution from Washington. The ethnographical interest of these objects is considerably enhanced by their historical and personal associations. Two corn husk dolls, for example, presented by the widow of the late J. N. B. Hewitt, who was the foremost authority of recent times on Iroquois culture and philosophy, are notable as being an exact reproduction of the dress of a man and woman of the Iroquois as described in contemporary accounts at the close of the eighteenth century. The Iroquois Federation of the Five Nations, founded in the seventeenth century, played a part of no little importance in the War of American Independence, though disrupted by a divided allegiance. The dresses of both male and female are of blue broadcloth decorated with glass, shell and porcelain beads and coloured ribbons. That of the woman is particularly elaborate.

Among Indian leaders in the war of resistance to the authority of the United States of the later nineteenth century, Sitting Bull, chief of the Sioux, won something of a world-wide reputation. Even in America, where at one time he was regarded as the worst of "bad Indians", he is now often made a 